\title{
In vitro plant regeneration from axillary buds of Hibiscus syriacus $L$.
}

\author{
Seo Bum Jeon ${ }^{1}$. Seung-Won Kang ${ }^{2}$. Wan-Soon $\mathrm{Kim}^{1}$. Gung-Pyo Lee ${ }^{3}$. Sun-Hyung Kim ${ }^{1} \cdot$ Sang-Gyu Seo ${ }^{1 *}$ \\ ${ }^{I}$ Department of Environmental Horticulture, The University of Seoul, Jeonnong-dong 90, Dongdaemun-gu, Seoul 130-734, Korea \\ ${ }^{2}$ Gene Research Center, Graduate School of Life and Environmental Science, University of Tsukuba, Tsukuba 305-0006, Japan \\ ${ }^{3}$ Department of Applied Plant Science, College of Industrial Science, Chung-Ang University, Anseong-Si, Gyeonggi-Do, 456-756, Korea
}

\begin{abstract}
Presently, we report a simple, reproducible and high frequency plant regeneration in Hibiscus syriacus L. using axillary buds. H. syriacus was regenerated from axillary buds directly or through a callus phase. Regenerated shoots were directly induced from young and fresh axillary buds cultured on Murashige and Skoog medium (MS) supplemented with $0.01 \mathrm{mg} / \mathrm{L}$ of the growth regulator thidiazuron (TDZ) after 2 weeks of culture. Directly induced shoots were transferred to hormone-free MS medium and root development was observed after 6 weeks. On the other hand, old and stale axillary buds were regenerated to shoots via callus induction on MS medium containing $0.01-2 \mathrm{mg} / \mathrm{L}$ TDZ after 4 weeks. A TDZ concentration of $0.01 \mathrm{mg} / \mathrm{L}$ was most effective in callus formation. Green callus was transferred to MS medium containing $0.01 \mathrm{mg} / \mathrm{L}$ a-naphthalene acetic acid (NAA) and $0.5 \mathrm{mg} / \mathrm{L}$ benzylaminopurine (BA). After 4 weeks, callus had developed into multiple shoots. Plantlets were formed from 10 week cultures of single shoots on hormone-free MS medium. Regenerated plantlets were cultured on MS medium for one month and then transferred to pots containing garden soil. Potted plants were acclimatized for one month and grown to maturity under greenhouse conditions. The present study has shown that various concentrations of plant growth regulator can be effective for in vitro plant regeneration of $H$. syriacus. The direct and indirect regeneration protocol presented here will be useful for understanding the manipulation and propagation of $H$. syriacus.
\end{abstract}

\section{Introduction}

Hibiscus syriacus L. is the national flower of Korea and is a popular ornamental plant in Korea. Many cultivars giving a variety of colors and diverse flower forms have been released. H. syriacus has been planted in various areas not only as an ornamental tree in the garden but also as a tree in the parks and on roadsides and in the central reservations of freeways. In addition, it is used in varied and economically important ways that produce fibres the production of fibre, and use as a beverage additive in some Asian countries (Hotta et al. 1989).

H. syriacus can be propagated by seeding and cutting. However, it is a heterozygous plant, so it is difficult to maintain genetic characteristics by seeding (Kim et al. 1998). Also, cutting is not always a proper propagation method because stock plants can be infected by virus. For in vitro plant regeneration, plant tissue culture can solve these problems and can be the basis of a mass production system. Micro-

*Corresponding author Tel 02-2210-5728 Fax 02-2210-2838

E-mail: atos13@hanmail.net propagation, is an important facet of plant biotechnology (Mangai 2001). It can produce many pathogen-free plants in a short period. In vitro plant regeneration system is very reliable and can meet the demand for providing disease-free, fast growing plants whose growth is not subject to seasonal constraints.

While early success in plant regeneration using the $H$. syriacus 'Honghwarang' cultivar were reported (Kim et al. 1998; Yoo et al. 1996), more recent efforts have been hindered by the difficulty in handling and establishing in vitro cultures of H. syriacus. The present paper reports the findings from two separate experiments designed to overcome the recalcitrance of $H$. syriacus. various combinations of plant hormone, concentration and application time were simultaneously optimized to improve regeneration efficiency of several $H$. syriacus cultivars including 'Pyeonggasan', 'Hwarang', 'Chungmu', 'Younggwang', 'Gakchang', 'Chungmu' and 'Saimdang'.

Materials and methods

Plant materials 
H. syriacus L. 'Pyeonggasan', 'Hwarang', 'Chungmu', 'Younggwang', 'Gakchang', 'Chungmu' and 'Saimdang' cultivars were used. The 'Pyeonggasan', 'Hwarang', 'Chungmu' cultivars were examined using indirect regeneration via callus induction. The 'Younggwang', 'Gakchang', 'Chungmu' and 'Saimdang' cultivars were examined using direct regeneration without the callus phase. Indirect regeneration used stale and old axillary buds. Direct plant regeneration used fresh and young axillary buds.

Axillary buds collected from axil tissues of $H$. syriacus cultivars were rinsed for a second using tap water. The tissues were then sterilized using an application of $70 \%(\mathrm{v} / \mathrm{v})$ ethanol for a minute, washed with distilled water and sterilized again using $50 \%$ (v/v) commercial bleach for 20 min using a magnetic stirrer. After that, these buds were rinsed with sterile distilled water five times and transferred to a lamina air flow bench prior to five rinses using sterile distilled water. After the final rinse, the buds were used for plant regeneration.

\section{Indirect regeneration}

For callus induction, MS medium (Murashig and Skoog 1962) supplemented with $30 \mathrm{~g} / \mathrm{L}$ sucrose was used. The $\mathrm{pH}$ was adjusted to 5.8 prior to addition of $3 \mathrm{~g} / \mathrm{L}$ gelite. After autoclaving for $15 \mathrm{~min}$ at $120^{\circ} \mathrm{C}$ and $1.2 \mathrm{~kg} \cdot \mathrm{cm}^{2}$ pressure, the medium was supplemented with $0.01,0.5$, $1,2 \mathrm{mg} / \mathrm{L}$ of a solution of the growth regulator thidiazuron (TDZ) prepared by dissolution in dimethyl sulfoxide (DMSO) and filter sterilization using a Nalge $0.45 \mu \mathrm{m}$ membrane filter.

Sterilized axillary buds were transferred to TDZ-supplemented MS medium and were cultured in a plant tissue culture room at $24 \sim 26^{\circ} \mathrm{C}$ under a $16 \mathrm{~h}$ photoperiod for 4 weeks. When the axillary buds had changed into a green callus, the medium was refreshed by MS basal medium containing $0.01 \mathrm{mg} / \mathrm{L} \alpha$-naphthalene acetic acid (NAA) and $0.5 \mathrm{mg} / \mathrm{L}$ benzylaminopurine (BA). After 4 weeks, the induced single and multiple shoots were transferred to hormone-free MS medium. Finally, plantlets formation from a single shoot culture occurred during 10 weeks incubation in hormone-free MS medium, which was refreshed every 3 4 weeks.

\section{Direct regeneration}

MS medium (Murashig and Skoog 1962) containing $0.01 \mathrm{mg} / \mathrm{L}$ TDZ was used for direct regeneration. Sterilized young and fresh axillary buds were cultured in this medium in a plant tissue culture room.
Directly induced shoots were transferred to hormone-free MS medium and cultured until the development of roots, with replacement of the medium with fresh medium every $3 \sim 4$ weeks.

\section{Acclimatization and transfer to soil}

Rooted shoots were maintained in hormone-free MS medium for a month. The in vitro rooted plants were taken out from the culture vessel and gently washed using tap water to remove residual agar, to minimize fungal contamination. The plants were transferred to plastic pots containing garden soil (Evergreen, Seoul-bio, Korea). The potted plants were acclimatized in the plastic acclimatization box for a month prior to their removal.

\section{Results and discussion}

\section{Indirect regeneration}

Old and stale axillary buds were employed for initial establishment of indirect regeneration. Axillary buds from each cultivar cultured in the presence of a various TDZ concentrations were formed callus to the callus form. After 2 weeks, 'Pyeonggasan' cultivar explants had increased in size and the axillary buds were swelled. Moreover, the buds had become bright green. With further time, explant diameters gradually increased. After 4 weeks of culture, the axillary buds had changed into green callus that showed maximum size (Figure $1 \mathrm{~A}$ and
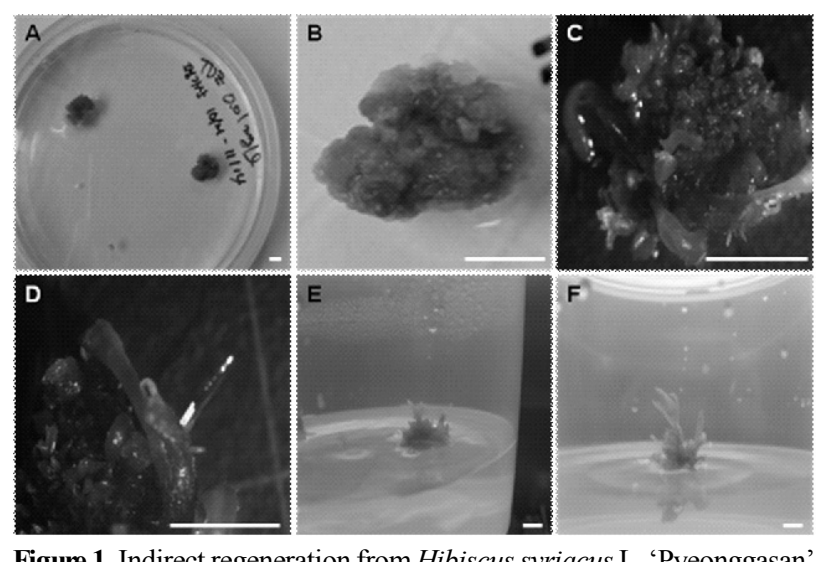

Figure 1. Indirect regeneration from Hibiscus syriacus L. 'Pyeonggasan' cultivar. (A and B) Green callus from axillary buds cultured on MS medium supplemented with $0.01 \mathrm{mg} / \mathrm{L} \mathrm{TDZ}$ for 4 weeks. (C and D) Multiple shoot was performed from green callus cultured on MS medium supplemented with $0.01 \mathrm{mg} / \mathrm{L} \mathrm{NAA}$ and $0.5 \mathrm{mg} / \mathrm{L}$ BA for 4 weeks. (E and F) Plantlets were formed after single shoots were cultured on growth regulator free MS medium for 10 weeks. White bars represent $5 \mathrm{~mm}$ 
Table 1 Effect of TDZ concentration on callus formation from axillary buds of Hibiscus syriacus $\mathrm{L}$

\begin{tabular}{c|c|c|c}
\hline \multirow{2}{*}{$\begin{array}{c}\text { TDZ concentration } \\
(\mathrm{mg} / \mathrm{L})\end{array}$} & \multicolumn{3}{|c}{ Callus formation rate $(\%)$} \\
\cline { 2 - 4 } & Pyeonggasan & Hwarang & Chungmu \\
\hline 0.01 & 80 & 0 & 73.3 \\
\hline 0.5 & 0 & 0 & 0 \\
\hline 1 & 0 & 0 & 0 \\
\hline 2 & 0 & 23.3 & 0 \\
\hline
\end{tabular}

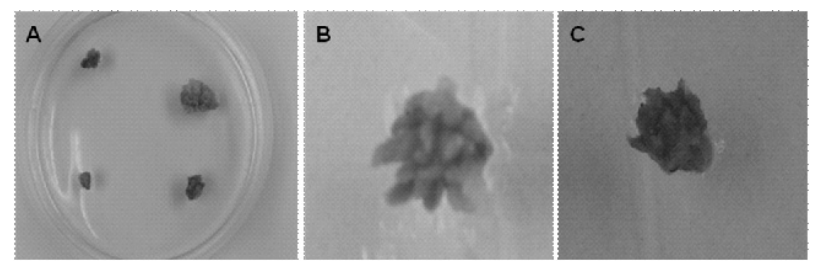

Figure 2. Withering of callus and axillary buds in the presence of 1.0 mg/L TDZ. 'Pyeongasan' (A), 'Purplerouge' (B), 'Chungmu' (C)

Table 2 Plant regeneration frequency from one callus clump of Hibiscus syriacus L

\begin{tabular}{c|c}
\hline Cultivar & No. of plantlets from one callus clump \\
\hline Pyeonggasan & 3.3 \\
Hwarang & 7.0 \\
Chungmu & 12.3 \\
\hline
\end{tabular}

Data are the average number from three replicates.
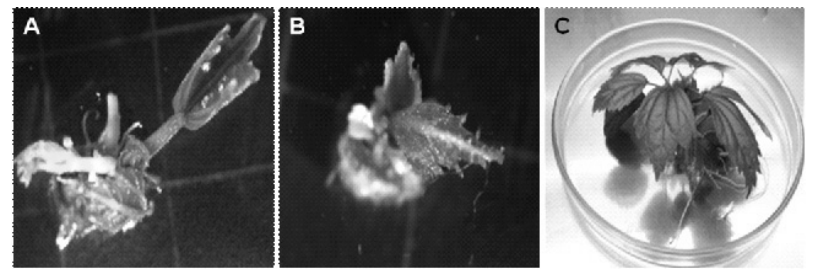

Figure 3. Direct shoot and root regeneration from young and fresh axillary buds of Hibiscus syriacus L. (A) Shoot elongation from 'Gakchang' cultivar in $0.01 \mathrm{mg} / \mathrm{L} \mathrm{TDZ}$ after 2 weeks of culture. (B) Shoot elongation from 'Yeonggwang' cultivar in $0.01 \mathrm{mg} / \mathrm{L} \mathrm{TDZ}$ after 2 weeks of culture. (C) Rooted shoots from 'Yeonggwang' cultivar cultured in hormone-free MS medium

B). TDZ concentration of $0.01 \mathrm{mg} / \mathrm{L}$ was most effective in callus formation in the 'Pyeonggasan' cultivar as well as the 'Chungmu' cultivar (Table 1).

TDZ is an effective growth regulator in woody plants that shows potent cytokinin activity at low concentration (Hueteman and Preece 1993; Kerns and Meyer 1987; Russel and McCown 1986; Singh and Bhatia 1988). Furthermore, being a non-purine cytokinin-like compound, TDZ has effects that are more potent than cytokinins in many species, and is also effective for shoot propagation and adventitious shoot organogenesis (Hueteman and Preece 1993; Lu 1993). Although
TDZ has many advantages for regeneration, cautious use is required for clonal micropropagation, since it can stimulate callus formation in addition to axillary shoot proliferation (Hueteman and Preece 1993).

At high concentration, TDZ produced withering of almost all axillary buds in the 'Pyeonggasan', 'Purplerouge' and 'Chungmu' cultivars (Figure 2). This may have been due to the TDZ-mediated stimulation of ethylene production, as observed in bean (Elstner et al. 1983). H. syriacus has also been linked with ethylene biosynthesis (Yoo et al. 1996). Thus, while a low concentration of TDZ can activate callus formation of $\mathrm{H}$. syriacus, a higher level may promote ethylene activity that is deleterious to callus preservation. An exception was the 'Hwarang' cultivar, which formed green callus in the presence of $2.0 \mathrm{mg} / \mathrm{L} \mathrm{TDZ}$. It may be that the demand for growth regulators differs from species to species. Therefore, different use of plant growth regulators is required in $H$. syriacus regeneration.

Multiple shoots were induced from green callus cultured for 4 weeks on MS medium supplemented with $0.01 \mathrm{mg} / \mathrm{L} \mathrm{NAA}$ and $0.5 \mathrm{mg} / \mathrm{L} \mathrm{BA}$ (Figure $1 \mathrm{C}$ and $\mathrm{D}$ ). The effectiveness of the combination treatment is consistent with a previous report describing promoted elongation of shoots in the woody plant Eucalyptus grandis (Luis et al. 1999).

In contrast, green callus did not generate to multiple shoots upon continuous subculture in MS medium supplemented with $0.01 \mathrm{mg} / \mathrm{L}$ TDZ. In peanut in vitro regeneration, continuous use of TDZ may not be needed for shoot induction (Kanyand and Prakash 2007; Kamal and Praveen 1992). After multiple shoots formed, they were transferred to hormone-free MS medium. Over the next 10 weeks, plantlets were formed from single shoots (Figure $1 \mathrm{E}$ and $\mathrm{F}$ ).

'Chungmu' was the best cultivar that exhibited the most effective regeneration from callus. On average, about 12 plantlets were formed from one callus clump (Table 2). Indirectly induced plantlets were cultured on MS medium for one month and then transferred to pots containing garden soil. Potted plants were acclimatized for one month and established in the greenhouse.

\section{Direct regeneration}

Direct shoots were induced from culture of axillary buds of $H$. syriacus 'Younggwang', 'Gakchang', 'Chungmu', and 'Saimdang' cultivars on MS medium supplemented with $0.01 \mathrm{mg} / \mathrm{L} \mathrm{TDZ} \mathrm{(Figure}$ $3 \mathrm{~A}$ and B). After 2 weeks of culture, almost $20 \%$ fresh axillary buds generated to plants (Table 3). Even if the same culture medium was used, young and fresh axillary buds were directly generated to shoots 
Table 3 Direct plant regeneration frequency from an axillary bud of Hibiscus syriacus L

\begin{tabular}{c|c|c}
\hline Cultivar & No. of explants & Plantlet formation \\
\hline Younggwang & 10 & 2 \\
Gakchang & 10 & 3 \\
Chungmu & 10 & 2 \\
Saimdang & 10 & 4 \\
\hline
\end{tabular}
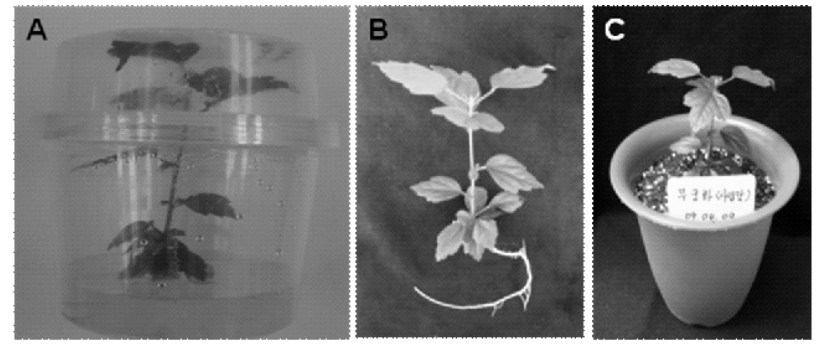

Figure 4. In vitro rooted plants of 'Saimdang' cultivar. (A) In vitro plant before transfer to soil. (B) Plant with healthy roots grown on hormonefree MS medium. (C) Appearance of plant following transfer to soil

without an intervening callus phase. This is consistent with the report describing regeneration of healthy young leaves and petioles to plants in H. syriacus 'Heikeyama' (Yang et al. 1995). Thus, explants age is very important to regeneration. Duong et al. (2007) reported that flower bud age plays an important role in morphogenesis based on a thin cell layer culture system, with aging plants tending to lose regenerative ability. Cell segregation and regeneration capacity differs between young and adult plant, with cell division occurring earlier in young Hedera helix and Anthurium andreanum plants than in their adult counterparts plants (Stoutemeyer and Britt 1965; Pierik et al. 1974). Thus, it seems likely that the timing of explant acquisition is important.

Directly induced shoots were transferred to hormone-free MS medium and roots were observed after 6 weeks. Rooted shoots were grown on MS medium and then transferred to pots containing garden soil. Potted plants were acclimatized for one month and then grown to maturity under greenhouse conditions.

In conclusion, $H$. syriacus was regenerated from axillary buds directly or indirectly. Direct regeneration was accomplished using young and fresh axillary buds through growth regulator of $0.01 \mathrm{mg} / \mathrm{L}$ TDZ. On the other hand, old and stale axillary buds were indirectly regenerated via callus induction. Callus was formed on MS medium containing $0.01-2 \mathrm{mg} / \mathrm{L}$ TDZ. A TDZ concentration of $0.01 \mathrm{mg} / \mathrm{L}$ was most effective in callus formation. Callus had developed into multiple shoots $0.01 \mathrm{mg} / \mathrm{L}$ NAA and $0.5 \mathrm{mg} / \mathrm{L}$ BA. Finally, axillary buds developed into plantlets on hormone free-MS medium and successfully regenerated to plants. Present study has shown that various concentra- tions of plant growth regulator can be effective for in vitro plant regeneration. The appearance of callus formation or plant regeneration differs depending on the cultivars and condition of the explants. The direct and indirect regeneration protocols presented here will be useful for further understanding of $H$. syriacus manipulation and propagation. Furthermore these protocols can be used basic step of Agrobacteriummediated transformation or particle bombardment transformation.

\section{Acknowledgements}

This work was supported by Korea Research Foundation Grant funded by the Korean Government (MOEHRD, Basic Research Promotion Fund) (KRF-2008-355-F00006)

\section{References}

Duong TN, Truong TTA, Nguyen TDH, Nguyen TD, Nguyen TH, Nguyen QT, Nguyen HV (2007) Effect of genotype, explants size, position, and culture medium on shoot generation of Gerbera jamesonii by receptacle transverse thin cell layer culture. Sci Hort 111:146-151

Elstner EF, Keller G, Paradies I (1983) Contrasting effects of the cotton defoliant thidiazuron and animoethoxyvinylglycine, an inhibitor of ethylene formation, on stomatal aperture and on ethylene formation in bean (Phaseolus vulgaris) leaves. Ber Dtsch Bot Ges 96:461-466

Hotta M, Ogata K, Nitta A, Hosikawa K, Yanagi M, Yamazaki K (1989) Useful plants of the world. Heibonsha, Yokyo, Japan, pp 1499

Huetteman CA, Preece JE (1993) Thidiazuron: a potent cytokinin for woody plant tissue culture. Plant Cell Tiss Org Cult 33: 105-119

Kamal AM, Praveen KS (1992) Regeneration in Phaseolus vulgaris L.: High-frequency induction of direct shoot formation in intact seedlings by N6-benzylaminopurine and thidiazuron. Planta 186:384-389

Kanyand M, Prakash CS, (2007) Evaluation of peanut genotypes for in vitro plant regeneration using thidiazuron. J Biotechnol 130:202-207

Kerns HR, Meyer, M (1986) Tissue culture propagation of Acer $\times$ freemanii using thidiazuron to stimulate shoot tip proliferation. Hort Science 21:1209-1210

Kim EY, Yoo YK, Kim KS (1998) Effect of thidiazuron on callus and multiple shoot formation in shoot-tip culture of Hbiscus syriacus L. 'Honghwarang'. Kor J Hort Sci Technol. 17:115117

Lu CY (1993) The use of thidiazuron in tissue culture. In Vitro Cell Dev Biol 29:92-96

Luis PBC, Adriane CMGM, Silvica BRCC, Ana CMB (1999) Plant 
regeneration from seedling explants of Eucalyptus grandis $\times$ E.urophylla. Plant Cell Tiss Org Cult 56:17-23

Mangai KG (2001) Tissue culture studies in some medicinally important plants. Plant Res 4:171-180

Murashige T, Skoog F (1962) A revised medium for rapid growth and bioassays with tobacco tissue cultures. Physiol Plant 15:473-497

Pierik RLM, Steegmans HHM, Mays J (1974) Plantlet formation in callus tissues of Anthurium adreanum Lind. Sc. Hort 2: 193-198

Russel JA, McCown BH (1986) Thidiazuron stimulated shoot differentiation from protoplast-derived callus of Populus. Plant Tiss Cell Cult Abstr pp 49
Singh S, Bhatia SK (1988) Shoot proliferation of pear cultures on medium containing thidiazuron and benzylaminopurine. Hort Science 28:803

Stoutemeyer VT, Britt OK (1965) The behavior of tissue cultures from English and Algerian ivy in different growth phases. Am J Bot 52:805-810

Yang LJ, Hidaka M, Masaki H, Uozumi T (1995) In vitro plant regeneration from leaf and petiole explants of Hibiscus syriacus L. Plant Tiss Cult Lett 12:173-17

Yoo EH, Yoo YK, Kim KS (1996) Effects of growth regulators, sucrose, light, and medium on callus and shoot formation in shoot-tip culture of Hbiscus syriacus L. 'Honghwarang' J Kor Soc Hort Sci 37:317-323

(Received June 5, 2009; Accepted June 23, 2009) 